\title{
HIDDEN COLLECTIONS: THE ELEPHANT IN THE CLOSET
}

THE WORK OF THE ARL TASK FORCE on Exposing Hidden Collections is moving us toward constructive action in our management of special collections. And more significantly, it is expanding awareness of special collections issues among those who can make things happen.

I have titled my presentation "Hidden Collections: The Elephant in the Closet" because this is often the way we think of these collections. We feel as though they are too large to fit through the door to leave the closet, and even if we shoved them out, how would we handle them? I am afraid that for a long time our hidden special collections have been viewed as an unwelcome white elephant we wished we didn't have. I don't know how many of you are aware of the origin of the phrase "white elephant." It goes back to the kingdom of Siam, where white elephants were owned by the royal family and considered sacred. They were protected and had to be well cared for. If you angered the prince, he would present you with a white elephant, which, unless you were as rich as the prince, would soon eat you out of house and home and eventually into ruin. We fear that our hidden special collections could consume our limited resources to the same degree. But the task is not insurmountable and that is what we what we need to keep in mind as we move forward.

I thought about elephants because I was thinking about Jim Haas, the distinguished retired president of the Council on Library Resources, who was famous for tackling seemingly insurmountable tasks. He always said, "How do you eat an elephant? You take the first bite." The brave and thoughtful authors of the white paper have done just that, and I think that we all believe that there is a second bite and more. That's why we're addressing these issues. 
Thinking about elephants also leads me to comment on teamwork, another notable achievement of this conference and of the white paper. Although many people have been working on the issue of processing special collections, we've been rather like the blind men and the elephant depicted in one of my favorite Hokusai prints. You're probably familiar with the fable: One blind man feels the elephant's trunk and believes he's feeling a snake, the fellow at the flank is sure the elephant is like a wall, and the one at the tail concludes that the elephant is like a rope. What we are doing is putting that picture together. We are assembling the broader overview that can only come through the pooled expertise of archivists, catalogers, rare book librarians, technologists, and managers.

I am going to leave this analogy in just a moment, but before I do, how about an elephant joke? Why do elephants have wrinkled ankles? Because they tie their sneakers too tightly. Nobody knows that? Here's another. What did the elephant say to Vladimir Putin? Nothing. Elephants don't speak Russian.

So what do you have to do to answer these silly questions? You have to shift your frame of reference, and that is what I want to spend some time thinking about. What is our frame of reference for addressing the seemingly insurmountable problem before us? I would like to a start with five assertions.

\section{Assertions: The Framework for Processing and Planning}

My first assertion is that there is no magic bullet. I know a lot of people wish I would stand here and tell you where to find that bullet, but there isn't one. What we do have, and I think the white paper makes this clear, is a modern arsenal of tools that has not been available until very recently. So my second assertion is that among the tools we must use is sustainable and searchable Web access at a variety of levels. We can now make our collections known at great distance because we have Web access. Third, I believe that in addressing these issues, catalogers and archivists need to spend more time together. Fourth, when we talk about processing hidden collections, we're not talking about our garden-variety cataloging backlog. That's a big enough headache, but this is something else entirely. Finally, although the problem is national and international, the solution is going to be local.

I want to talk about the first three assumptions as a group because, as the white paper makes clear, they are all intimately interconnected. Taken together, they help us to formulate a framework for processing. What I find 
interesting, and I speak from the perspective of a former cataloger who is now a director, is that for years, archivists and curators have been doing amazing things to process special collections. They have been devising collection-specific ways of handling holdings. They've been dealing with pamphlets, images, papers, and manuscripts. They've been designing finding aids that range from box lists to item inventories to indexes, and they've put all these tools first on typed sheets of paper and then in card files and then in databases (albeit databases that sometimes could not be opened three years later because the software wasn't made anymore).

However, all of this descriptive information was accessible only on-site. You'd have to come and find out what was available. And for at least the past thirty years, catalogers have been somewhat critical of these methods. They've bemoaned the lack of standards, the fact that the access is only on-site, and the fact that the databases weren't really sustainable because they weren't standard. But what we catalogers didn't quite get is that although we had correctly identified the problem, we did not have the solution. We had standard cataloging rules that did not work for special collections and practices that did not apply.

It's only been in the past five years or so that we have been able to begin to put all of this together thanks to the emergence of new tools to address these old problems. There is the development of EAD, incredibly groundbreaking work that is still going on to make it widely applicable. Digital library development has been extraordinary because suddenly one can manage digital files and objects in sustainable ways. We also need to look carefully at some of the very newly emerging digital library metadata standards and technologies for managing access to information. These now allow us to make decisions and to know that any of the options is sustainable. Are we just putting in a collection-level record? Can we click from that record down through a finding aid? At what level of detail is that finding aid? We can make it from the finding aid to a list and from the list to an object surrogate. There is a sustainable, shared methodology for doing this. We now truly have options for processing special collections that we didn't have before.

It was thinking about these issues that helped me realize how recently all of this has come to pass. It's going to affect our thinking, and it's why we can and should have to do more to take advantage of our new tools. We can have a processing framework that combines the best of the old and the new. We need to retain the emphasis on flexible, collec- 
tion-specific approaches. We need to draw on cataloging, archival, and digital library techniques and technologies that we can mix, match, and meld. We've come a long way. That's one reason the timing of the Exposing Hidden Collections initiative is so good, because we now actually have the toolkit we didn't have before.

I think that my fourth assertion is somewhat obvious. We're not talking about a cataloging backlog in the sense that catalogers typically do. First, it's not a backlog because a backlog implies that there's a flow, and what we have here is an unexcavated well. Nothing is flowing; that's the point. Moreover, these backlogs cannot be eliminated in the same ways as a typical backlog. Many of my colleagues know how passionate I am about cooperative cataloging and how much time I have given to it. But that's not the framework here. These are unique collections and, therefore, this problem is not going to be solved by using other folks' cataloging records.

That gets us to my fifth assertion: Although the problem is national, the solution has to be local. Our framework for planning has to be based on a system of institutional responsibility. Let me quickly point out that this does not mean that there are no areas for collaboration. In fact, we just talked about the kind of teamwork that is needed, and we need that across institutions as well as within them. And it certainly does not mean that individual institutions have all the resources they need. If that were the case, you could pack up, go home, mind your knitting, and it's all fixed. That would be the magic bullet. But we do have to start with institutional responsibility and then build from there. The work of the ARL task force articulates how the acquisition and processing and service for unique documentary collections are a core function of research libraries. I wish to emphasize the concept of core function. I realize that for most of us, that doesn't sound like a big discovery. Still, it is a message we need to get across. These are the collections on which new knowledge in the humanities is built. Scholars rely on this overall mosaic of primary collections. Each of us contributes just a piece of that, our little tesserae, to make the full picture. It is our institutional responsibility to deliver access to the pieces we hold.

IOSO: Internalize, Organize, Strategize, Optimize

Thus, our core framework for action rests on each institution's responsibility. I've coined an acronym here (although I doubt it will have legs): IOSO. It's not so easy to say, but it stands for Internalize, Organize, Strategize, and Optimize. Allow me to explain. 
Internalize. We have to recognize that special collections are a core program of a research library, and that means some reallocation. Our institutions must start by internalizing the responsibility for special collections. So, speaking to my fellow ARL directors: Are your circulation statistics perhaps down, as is the national trend? Consider some wiggle room for reallocation to processing hidden collections. Is there an acquisitions endowment that we can get away with turning to processing for a few years? Buy less for a while and process more.

Organize. Organization is very important, and it is especially important to build special collections that are integrated into the organization. This may grate a little bit because I realize that for many heads of special collections there's something special about being special. But, also it means that you don't have others in the organization worrying about you. Your backlogs should be the headache of the director of technical services. That's the same person who in most of our libraries has probably broken through the garden variety backlogs already, who has made processing more efficient. Our directors of technical services have made terrific progress in the past fifteen years or so in processing standard collections. Now, those folks need to get up in the morning worrying about what to do with special collections. But they're going to need some new expertise and some different team configurations in order to do that. And that's the point-that interdepartmental teamwork and the resources necessary to support it can only be marshaled by a librarywide effort, supporting teams of catalogers, archivists, curators, digital library technologists, and managers to figure out how it all comes together. That's why the organization and being organized within it are so important.

Strategize. Every institution needs to have a strategic plan for addressing its unprocessed special collections. I think that is much more important than, say, a national survey. What's most important is that each institution has its own survey and its own plan. Getting your act together at home is the critical part. A recent very good example is the work done by the Historical Society of Pennsylvania with a grant from The Andrew W. Mellon Foundation. I know that Columbia is building on that work and that work, in turn, built on earlier efforts in both North and South Carolina. The Historical Society developed a model for assessing the differences in priority among collections and determining the appropriate processing for each. It sets out a methodology that could be adapted to different institutions. 
Optimize. Of course, you can't do everything at once, so it's terribly important to analyze and prioritize. Every institution has to do that for its own collections and, as we do that, we need to optimize. Part of planning involves crafting the optimal processing plan specific to each collection, choosing the appropriate tools, and choosing the appropriate level for each collection.

These things are hard to do and, with the modern arsenal, the new toolkit that has emerged in the past few years, most of us don't know how to approach it. How many of us have the big overview? How many people know how to weave this all together? We need a lot of help to take on our institutional responsibility. Fortunately, IOSO does not mean isolation. I think that the planning we are doing now is planning to help institutions help themselves. We have organizations involved that have a long history in helping organizations help themselves.

\section{The Preservation Planning Model}

As I thought about tackling this large-dare I say, elephantine-problem, I realized that we have a very good model in preservation. I remember when we were literally inventing library preservation programs. I can remember when it dawned on ARL libraries that we had a new responsibility. It was not new, of course, anymore than these hidden collections are new. Those books had been crumbling away in our stacks all along, but we realized that we had to do something, that we essentially had to IOSO preservation. (See, IOSO is a verb, it's a noun, it's whatever you want it to be.) And in doing that, we were extraordinarily successful, especially when you think about what we accomplished from nothing. Perhaps you remember that ARL sponsored institutional self-studies because institutions really didn't know how to set up preservation programs, survey their collections, or do internal strategizing. We needed methods and tools and best practices. Then we had to document and develop manuals for them. There was training and education. We developed regional service centers and cultivated funding sources thanks to leadership from a variety of organizations. This was an entirely new field. The task of special collections processing is small compared to inventing the field of preservation.

I put forward that model because it started me thinking about how we can facilitate the processing of our special collections. What does the preservation model suggest that is applicable to the situation we have? One of the things I just talked about was institutional self-study, which must certainly be part of this kind of strategic plan. Assess your 
collections. What is their level of research value? How do they need to be processed? What will it cost you to process them? We need more development of best practices and standards. As the white paper points out, many of these standards exist. But how much is there? How do we bring them out? And how many people know how to use them? What kind of documentation and manuals do we have? What kind of professional development do we need? There are some great examples in the white paper of bad ways to process collections (such as a single collection-level record for 95,000 pamphlets on the Great War) and of processing that would be done entirely differently if undertaken now. How do we train people to make those judgments, which must remain collection specific? Professional development and sharing of expertise are extremely important tools. I also have been told again and again that we really don't have software for managing special collections. We don't have the equivalent of your core bibliographic system that helps you bring things in and move them around efficiently and know what you are doing with them. We're capable of developing those software tools. And for all of this, of course, we need more money. So we should be talking in the next day or so about how we can help lobby for funding.

What I don't want us to do is sit around and wring our hands and say we don't have money so we can't do anything because that's not the case. Besides, you never get money unless you have some really good plans. Think, for example, about how the NEH has been developing a focus on American history. Then look at how many of our hidden collections can support that interest and can support education. NEH has money for processing special collections, although we would like it to have more. So, one thing we must do is lobby for that.

Some of you will remember that the old Higher Education Act Title IIC program was a very effective funding source for processing special collections. Unfortunately, the program was discontinued and, also unfortunately, we were using its funding before we had the tools we have today. IMLS is the inheritor of many of those HEA programs. The question now is how we can shape a modern special collections access program for IMLS. Another thing we need to do is to share experiences in cultivating private foundations. Except for the wonderful Mellon Foundation, they are not, for the most part, going to be interested in the generic problem, but they are going to be interested in specific subjects, specific institutions, specific plans you have. If we can help to bring out those subject areas and share ideas about them, we should work together to do that. 
We need to develop a multipronged approach. This is not a search for one magic bullet; rather, it is a search for a suite of actionable initiatives. What we have to do in the next day and a half is identify the mostneeded professional development and training programs; the mostneeded assistance programs for institutions; the standards, methodologies, and practices that need to be developed or need to be brought into a form where more people understand them. That's where the tools, manuals, and documentation come in. We need to be thinking about which things we should do first to get to this point. And, of course, anybody who has ideas about funding activities should speak up. If you are going to make your planning effective, you have to decide where the buck stops. Who has responsibility for different activities? Don't just say, "we need." Say, "we need ... and one of these folks will do it." Because "these folks"-ARL, CLIR, RLG, RBMS, LC, OCLC, SAA, and others-are all involved. That's what makes this initiative so positive. We have to be making to-do lists for each of these organizations. It's great that ARL has pulled us all together, and some of these to-do lists will be back on ARL's plate, but there are plenty of lists to go around. I will say again that this is a complex, multifaceted problem and solving it requires teamwork.

I would like to close by returning to elephants and recalling another Hokusai print. This time, he shows a team washing an elephant. Actually this print is called "A Mammoth Task." That's perfect. We are going to have to extend our reach, and I think, thanks to the good work that's been done already, we are going to have an opportunity to make a difference. It's just the beginning of a new era in making special collections accessible, and we have a lot of work to do. 